\title{
English-Chinese Translation Course Design Based on Collaborative-autonomous Learning Mode Under Web Environment
}

\author{
Yuanyi Yang ${ }^{1, a}$, Yangrui Zhang ${ }^{1, b}$ \\ ${ }^{1}$ Foreign Language Department, Pingxiang University, Jiangxi, China \\ a carrie_yi@163.com, bxzyr@sina.com.cn
}

Keywords: English and Chinese translation, Collaborative learning, Translation teaching, Constructivism, Network.

\begin{abstract}
Under the guidance of constructivism theory, the new mode of English-Chinese translation course is divided into four modules: theory study, skills learning, translation practice and summary and reflection. With their respective features, each module is assigned with different teaching objectives and content of collaboration.
\end{abstract}

\section{Introduction}

English, one of the most popular international language, has been playing a critical role to enhance cultural and commercial intercourse and communication among countries in today's increasingly global environment. In 2015, Chinese ministry of education published the Revised Syllabus for English Majors in Colleges and Universities, which indicates English major aims at fostering talents with both solid English foundation and extensive cultural knowledge, and ability to translate, teach, manage and research with English in foreign affair, education, business, culture, technology, and military affair. It also suggests colleges and universities to offer translation and interpretation training as one of English major's professional skills.

English-Chinese translation has been taken as a major course for English majors and an indispensable part of talents training. But translation skill still remains a great barrier for English majors, who find inefficient in improving it. For one thing, translation is a high-demanding expertise that is not easy to master; for another, the teaching of translation is somewhat behind the times.

Collaborative learning model makes full use of network resources, advocates teamwork and autonomous learning mode, extends the study outside class, trains translation theory and practical ability, and develops the translation of auxiliary skills.

\section{The theoretical basis of collaborative-autonomous learning mode}

Concept of Collaborative self-learning mode. The so-called collaboration refers to collaboration in work, that is, many people planned to work together in the same production process, or in different but interrelated production process. Johnson brothers of University of Minnesota believe that collaborative learning refers to maximize the learning efficiency through the collective participation of students in the form of groups in class.[1] Therefore I believe the collaborative-autonomous learning mode is the learning process when in English-Chinese translation classroom, the teacher organizes the learners to cooperate in the form of groups to complete the same goal through the group communication, interaction and consultation. .

Theoretical Basis of Cooperative Autonomous Learning Mode. The shortcoming of traditional teaching lies in attaching more attention to theory than practice. Constructivism learning theory make up for the deficiency of traditional teaching theory, and provides a theoretical guidance. 
For new teaching mode. Constructivism is student-oriented, and the first advocate, Piaget, argues that knowledge is neither from the subject nor from the object, but is established during the interaction of the subject and the object [2]. In other words, the acquisition of knowledge is not from the input of teachers, nor the passive acceptance of learners, but through the interaction between the two and in the teaching. Constructivist argues that knowledge is obtained during meaning contruction by learners in a given context, with the help of others, using the necessary learning materials. Constructivism focuses on the process that learners take the initiative to construct knowledge, and particularly emphasizes the importance of context creation, collaborative learning and learning environments. Learners don't accept external information passively, but construct the meaning of the current things after taking the initiative to choose, and process the external information according to their own experience[3].

Features of Cooperative Autonomous Learning Mode. Under the guidance of the learning constructivism theory, the cooperative self-learning mode has the following characteristics: 1 . It is student-oriented. Students are guided to explore and tap into knowledge in form of task. After analysis, test, and even criticism, they complete the construction of their own knowledge. 2. It is scenario-oriented. In class, students are required to complete different translation tasks under simulate scenarios. They will experience the real translation project by playing project manager, translator,reviser and other roles in the process. In this way, students are able to experience the translation practice on their own. 3. It is collaborative learning. Collaboration and communication are important means, and will run through the entire learning process. The teacher ensures that each learner's ideas are shared to the entire learning group, and the team's fruit come from the team members of the coordination and cooperation.

\section{Design of Cooperative Autonomous Learning Mode}

As mentioned above, the cooperative teaching mode combines the traditional teaching with the network and electronic information technology, focus on the participation and self-learning of the students. Based on the teaching program, the cooperative self-learning mode is divided into four modules: theoretical study, skill learning, translation practice, summary and comments. Each module will complete the different learning content to achieve different teaching objectives in a cooperative way.

Students are grouped first, with 3-4 members and balanced capacity per group, taking into account students' expertise, computer operating ability, personality, communication skills and other factors. Each group selects a team leader. As the network is a prerequisite, it should be ensured that each group has at least one networking computer.

\section{Design of theoretical study}

Teaching objectives. To learn the relevant translation theory; to form basic macro-understanding of translation; to train information retrieval, sorting ability, especially the ability to retrieve information from original language and to sort out valuable information in the huge amount of network resources; to train the organization and coordination ability, making sure that one can quickly achieve self-positioning in the team and serve the team; to enhance the communication ability.

Teaching content. Major schools of translation theory (linguistics, hermeneutics, functionalism, deconstructionism and feminism); their definition of translation, standards and process of translation, quality of translator, and etc.; their main representative figure, works, and influence on translation style and so on.

Teaching steps: step 1. Preparation: Post the theme of each lesson before class. Each group is responsible for a theme. Students are required to work in group and carry out relevant information retrieval, make a report , and present in class. The contents of the report should include the main representative of the translation theory, the core view of the translation theory, the representative works and the impact on the current translation style.

Step 2. Presentation: the team show their results of collaboration to the class; each member are assigned a certain amount of the report. 
Step 3. After report: Other students ask questions about the group's report, and the teacher summarizes the contents of the group and comments on the group's performance.

Design analysis: "Theory is hierarchical, and the theory of micro - level has concrete guiding significance to practice. The theory of meso - level can describe and explain the phenomenon, and the theory of macro - level has the function of reconstruction theory. [4] The theories involved in this section include both the theory of meso-level and the theory of macro-level. They are quite academic, abstract and the relatively boring to learn. A good way to integrate students is to change student's role from the recipient to a lecturer so as to promote their interest and participation. I select several major schools of translation theory in the translation circle, and plan to have students learn the translation theory by understanding their ideas. Each group will claim one school to give a comprehensive understanding of the school's theoretical thinking and to report.

This part is designed to conduct collaboration in two level: the micro and the macro level. In micro level, the group member collaborate to introduce a school of translation theory with the intention help students master the translation theory through the division of labor within the group. In macro level, groups fruit as a whole is the macroscopic understanding of translation theory. The group present to the class their collaborative fruit, which would be digested and acquired through the questioning time. In this way, each theme has been shared.

Students must have a preliminary understanding of the theory before presentation. To complete the report, they must do a lot of information retrieval, get familiar with the theoretical background and development, sort out key information and draft a report text. This process involves task of information retrieval, information selection, text drafting, presentation and etc, which will be assigned to students in accordance with their capability.

\section{Design of Translating skill study}

Teaching objectives: to master the translation skills, lexically and sententially; to be able to identify and understand the application of translation skills; to appreciate the pros and cons of translation text;

Teaching content: lexical translation: the selection of words, extension of words; conversion of word class; amplification; omission; translation of positive and negative sentence. Sentence translation:passive voice; noun clause; attributive clause; adverbial clause and long sentences.Translation of idioms and new words, and punctuation processing.

Teaching steps: step 1. Preparation: each group is assigned a translation skills, and required to work together to master the concept, application, examples, and special cases of the skills.

Step 2. Presentation: groups take turns to elaborate their fruit to the class in detail.

Step 3. Application of translation skills: teacher gives an text for groups to translate.

Step 4. The teacher summarizes and comments on students' translations.

Design analysis: this part is a transition from theoretical study to the practice. It includes both micro-theory study, and also translation training. Teaching content goes from the easy to the complicated, first vocabulary translation, and then sentence translation, and finally the chapter.

Apart from principles, the mastery of translation also needs a lot of exercises and practice. In this part, an application section is added with the purpose of training students to apply the translation skills comprehensively. Teachers can select some typical sentences for students to translate, then gives comments on the performance of the students especially the translation performance, whether the translation skills are used properly, and explain to them different translating methods have different effects.

\section{Design of translation practice}

Teaching objectives: to understand the characteristics and translation methods of texts; to be able to determine the professional fields of the original text; to understand the terms in various fields, and form their own termbase; to learn to use translation auxiliary softwares, and be able to 
use them to complete their own or team tasks; to be familiar with the translation process and can be qualified for each part of the processes;

Teaching content: the use of translation software; translation training in the fields of literature, economics, trade, law, tourism, machinery, science and technology, journalism and other fields

Teaching steps: step 1. Preparation: decide the professional fields of this class, requiring the group to translate an article of 1000 words in the professional field, and present the translation in the class. The article should be carefully selected from the Internet and should be translated on translation software. Every member should at least play a role in the process,including the project manager, translator, reviser and etc. The presentation includes the language feature of the, the professional terms, the skills and methods of translation, the duties and division of the members, and the difficulties and solutions in the translation process.

Step 2. Presentation: each group in each class take turns to present their results as required, including the division of labor and responsibilities of the members, the selection of the original text, the language feature of original text, the translation techniques and methods of the translation, the establishment of the corpus and the termbank, their feelings and experience and so on.

Step 3. Teachers make the overall evaluation on the professional field of text features and translation requirements; give comments and analysis on the translations; give evaluation on collaboration and division of team members; give answers to the questions and doubts from students.

Design analysis: Translation practice is the key part of this course. It picks seven common fields in English and Chinese translation, dividing into seven sections. It aims to strengthen the understanding of translation theory, be skilled at translation skills and get to know different professional fields, so that students can achieve mastery through a comprehensive study of subjects.

Before the formal procedure, teacher must elaborate on the requirements, and explain to the students the translation process and the use of translation software, so it needs two additional hours to explain these in detail.

Teacher does not assign original text while doing translation practice as students need to first understand the writing habits of the professional field and select the original text in order to develop students network search ability and article appreciation ability, however, teachers still needs to give advice to the selected article before they start translating thus guiding to the right route.

Translation process is divided into three part,project manager, translator, reviser, which is indispensable in actual translation. According to the needs, there can be more detailed division, such as: typesetting, term specialist, technical specialist, quality control, editor and so on. The better understanding of the translation process, the more conducive for students to simulate the real translation process in practice, thus the formation of real feelings.

\section{Design of summary and comments}

From previous design, we understand that comments and summary part is deeply involved in the other three part. It can be seen as the crowning touch of each procedure, so unlike the other three, this part is not separated, but integrate into the previous teaching design. Each section has a small period for comments, a theme has a theme review, and a procedure an overall review.

The form of Summary and comments: student's self-evaluation + team evaluation + mutual evaluation among groups + teacher's general comment

Summary and comments include: 1 . Student self-evaluation: learning outcomes and feelings and experience from collaboration; 2 team evaluation: group results, obstacles and difficulties in the process of collaboration, and things needs to be improved;3. Group evaluation: the most impressive team and its distinctive feature; 4. Teacher's evaluation:systematic summary of theory to hold a macro awareness; group performance; outstanding performance of team member; the team's performance, and the proposed improvement during cooperation.

It can be seen that teacher's comments and summary mainly focus on the summary of knowledge, and takes into account the students' gains and experiences. While comment from 
students focus on collaborative process. The two work together to complete the summary and evaluation.

The purpose of the design: 1 . to help students conclude and sort out knowledge and form a systematic framework; 2 . To guide and rectify students during collaboration so that teamwork will be more harmonious and reasonable; 3 to help teacher understand process of their study, form comprehensive process evaluation, and adjust teaching progress and difficulty timely.

\section{Summary}

There is no teaching material in this course, but a syllabus is issued to the student. Students are required to prepare for the course according to the syllabus' requirements. The four stages of translation teaching are progressive, interlocking, and strive to equip students with basic translation theory and ability. Collaborative-autonomous learning mode is distinctive as learning content is combining with the Internet information to ensure the most updated translation theory, skills, and materials; network information retrieval is an indispensable skill, through which learners' autonomous learning ability and knowledge construction is developed after their analysis, criticism and verification of various network information; network translation platform is applied to simulate the translation process thus translating practice and training are conducted simultaneously; and the emphasis on teamwork enhances learning motivation.

\section{References}

[1]Johnson, D.W. \& Johnson, R.T. Toward A Cooperative Effort [J] Educational Leadership, ASCD Publications. USA, 1989,46:80-81

[2] WN Peng, GY Jia Contructionism Theory \& Teaching Reform - a Summary of Contructionism Learning Theory [J] Theory and Practice of Education, China,2002,22:17-22 In Chinese

[3] Chuan Xiao On Student's Subjectivity from Constructionist Learning View[J] Education Research and Experiment, China,1998,4:1-5 In Chinese

[4] ZJ Yang Thoughts on Translation Study[A], Translation Study toward 21 Century[C] Beijing: The Commercial Press, 2002 In Chinese 